\title{
The cost of healthy and sustainable diets as purchased by consumers in Scotland
}

\author{
S. Whybrow ${ }^{1}$, G.W. Horgan ${ }^{2}$ and J.I. Macdiarmid ${ }^{1}$ \\ ${ }^{1}$ Rowett Institute, University of Aberdeen, Aberdeen AB25 $2 Z D$ and ${ }^{2}$ Biomathematics and Statistics Scotland, \\ Aberdeen, AB25 2ZD.
}

This abstract was presented as the Public Health Nutrition Theme highlight.

Food choice in Scotland results in an average diet that is far from that recommended in the Revised Dietary Goals for Scotland (RDGS). Total fat, saturated fat and sugar contribute more to energy intake than is recommended ${ }^{(1)}$. Salt intakes are also higher, and intakes of fruits, vegetables and oil rich fish are lower than recommended amounts ${ }^{(1)}$. In addition, relatively high intakes of meat and dairy products are contributing to climate change through their associated greenhouse gas emissions (GHGE). Cost is often perceived as a barrier to adopting healthier diets, with healthier diets tending to be more expensive than less healthy ones. The relationships among healthiness, environmental impact and the cost of dietary choices are complex, however. This study examined the costs of purchasing healthier diets compared to more sustainable diets by households in Scotland.

Household $(\mathrm{n}=2844)$ level food and drink purchases (excluding those consumed outside the home) recorded by Kantar Worldpanel (KWP) were adjusted for waste ${ }^{(2)}$ and scaled for household composition to give amounts "as consumed" per adult equivalent. GHGE of each household's food and drink purchases were estimated by linking the 2091 food groups that were defined by KWP for retail purposes, to foods and environmental data ${ }^{(3)}$. A Diet Quality Index (DQI) was calculated, based on the RDGS, with scoring from 0 (lowest) to 100 (highest). Households were categorized into tertiles by DQI score and by GHGE per MJ as purchased.

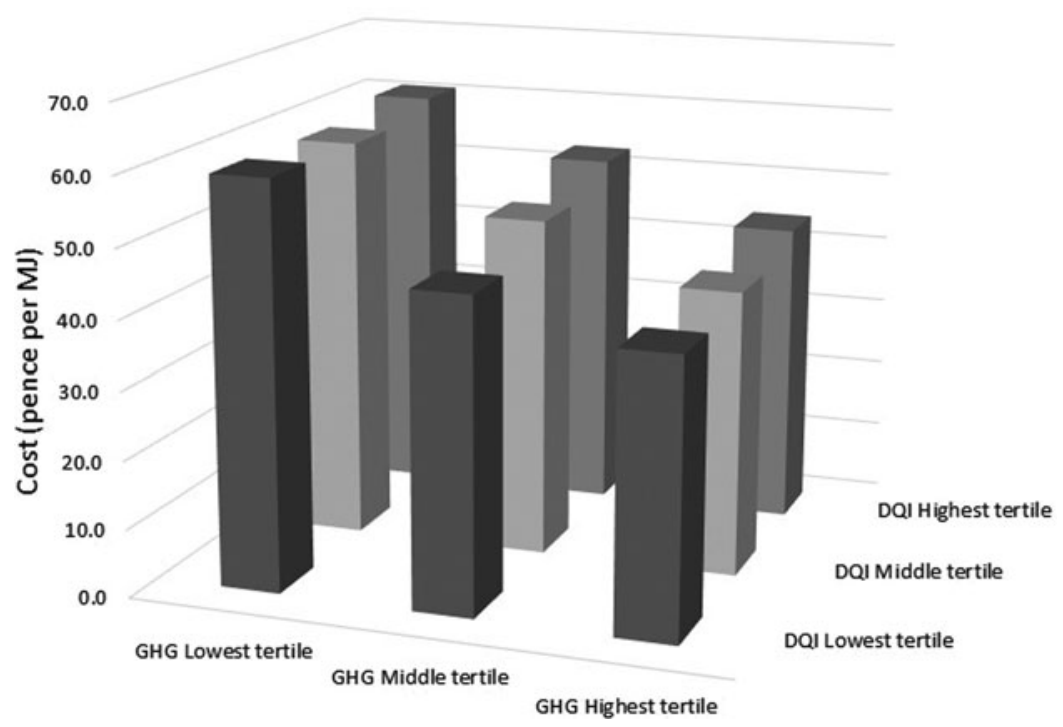

Mean DQI score was low at 41.7 suggesting that, on average, few of the RDGS were being met. Households in the highest tertile of DQI score had the most expensive diets, although the difference across tertiles was not great $(50 \cdot 4,49 \cdot 1$ \& $52 \cdot 0$ p/MJ from the lowest to highest tertile, $\mathrm{P}<0 \cdot 001)$. Diets with lower GHGE were more expensive than those with higher GHGE (59.7, $49 \cdot 5$ \& $42 \cdot 329 \mathrm{p} / \mathrm{MJ}$ from the lowest to highest tertile, $\mathrm{P}<0.001)$. There was an interaction between DQI and GHGE in their association with the cost of the diet $(\mathrm{P}=0.004)$, with healthiest and most sustainable diets being more expensive than the least healthy and least sustainable diets (61.0 and $40.2 \mathrm{p} / \mathrm{MJ}$ respectively). Healthier diets were not necessarily more sustainable.

If higher cost is perceived as a barrier to purchasing healthier diets, then it is likely to be an even greater barrier to the more sustainable diet choices. This presents difficulties for the promotion of healthy and sustainable diets.

1. Food Standards Scotland (2015) The Scottish diet: it needs to change. Aberdeen; Food Standards Scotland.

2. WRAP (2013) Household Food and Drink Waste in the United Kingdom 2012. Banbury: Waste and Resources Action Programme.

3. Barilla Center for Food \& Nutrition (2015) Double Pyramid 2015: Recommendations for a Sustainable Diet. Rome: Barilla Center for Food \& Nutrition. 